\title{
Access of Discharged Schizophrenia Patients to Employment and Association Memberships in Turkey
}

\author{
Nermin Gürhan ${ }^{1 *}$, Neşe Uğurlư², Burhanettin Kaya ${ }^{3}$ \\ ${ }^{1}$ Psychiatric Nursing Department, Health Science Faculty, Gazi University, Ankara, Turkey \\ ${ }^{2}$ T.C Gülhane Military Medical Academy, Department of Nursing, Psychiatric Nursing Department, Ankara, Turkey \\ ${ }^{3}$ Antalya Specialty Medical Center, Antalya, Turkey
}

*Corresponding Author: Nermin Gürhan, Associate Professor, PhD, RN T.C. Psychiatric Nursing Department, Health Science Faculty, Gazi University, Besevler, Ankara, Turkey. Email: nermingurhan@gmail.com

Received August 10, 2016; Accepted September 5, 2016; Online Published December 18, 2016

\begin{abstract}
Background: Patients with schizophrenia can experience a deteriorated performance in many of the skills needed in daily life, the workplace, the family circle, or in social interactions.

Objective: This definitive study used comparison to evaluate the functionality, treatment compliance to therapy, and styles of coping with stress of schizophrenic patients who work and are members of an association.

Methods: The individuals participating in this study were divided into four groups. Group 1 were members of an association and employed; Group 2 were members of an association and unemployed; Group 3 comprised non-members who were employed; and group 4 were non-members and unemployed. A total of 60 patients (15 in each group) comprised the sample. Data was collected by means of the Individual Information Form, the Adaptation Rate Scale for Medical Therapy, the Functional Recovery Scale in Schizophrenia Patients, and the Scale for Coping with Stress. Statistical analyses and interpretations were conducted using frequency and percentage, $t$ test, and analysis of variance (ANOVA) to assess the data. Results: It was observed that being a member of an association and working at a job affected the social and occupational functionalities in schizophrenia patients participating in the study, but the styles of therapy adaptation and coping with stress did not affect these areas.

Conclusion: Results indicated that the use of current antipsychotic drugs did not affect functional areas, therapy adaptation, or styles of coping with stress.

Keywords: Schizophrenia, Functional behavior, Psychology, Therapeutics, Psychological, Commerce
\end{abstract}

\section{Background}

It is becoming more and more difficult in today's world for a healthy individual to find and maintain employment and gain economic freedom; maintaining a job can be even more difficult and challenging for someone diagnosed with schizophrenia. ${ }^{1}$ Diverse issues cause this difficulty; stigmatizing views and discrimination, the risk of harm in a workplace, and inappropriate type of job have as much influence on employment as the disorders such people have in reasoning, cognitive functions, affection, and conduct. ${ }^{1,2}$ Any of these reasons could cause a patient and/or her/his family to be hesitant about entering the labor market. One treatment method used to eliminate such hesitation is vocational rehabilitation followed by supported employment. With this method, schizophrenia patients are introduced to and supported in a working environment. As a result, they have a better social life and improved prognosis. They can be assured of regaining their self-management and a financial hold. A reduction in the frequency of relapses of the illness also occurs, and healthcare costs are reduced, which also increases a patient's functional capacity. A patient's family and the public are enlightened about the positive effects of supported employment, and the patients themselves are effectively supported in their workplace in an effort to help them make positive progress in every sense. ${ }^{1}$

Apart from a deterioration of functionality in the workplace, a schizophrenia patient can also experience deteriorated performance in other areas, such as in the skills for functioning in daily life, the family circle, and social interactions..$^{3-5}$ Consequently and inevitably, such a deterioration negatively affects the individual, his/her family, and the society in which s/he lives. ${ }^{2}$ The patient experiences such a downturn that he tends to lock himself at home, retreating from social and public life, and begins to have difficulty satisfying his daily needs and managing his self-care. ${ }^{1}$ After a while, the patient may refuse to take responsibility for activities such as household chores and shopping or the family may hold them back from taking such responsibilities. ${ }^{6,7}$ There can also be a decline in

Copyright (C) 2016 The Hospital Practices and Research. This is an open-access article distributed under the terms of the Creative Commons Attribution License (http://creativecommons.org/licenses/by/4.0), which permits unrestricted use, distribution, and reproduction in any medium, provided the original work is properly cited. 
other activities, such as sports or attending the theater or cinema, and the patients themselves cannot even perceive what their hobbies are. Being a member in an association for people with schizophrenia and their families boosts a patient's adaptation to the external world. It enhances his/ her skills for social interaction and supports them with skill training (helping develop behavior patterns needed for life); it encourages social activities such as attending the theater or cinema and hobbies such as painting and bead design. Such associations also provide psychoeducational training and support to these patients and their family members, sharing with them the experiences and difficulties of a life with somebody with schizophrenia. A joint approach is designed to address stigma in an effort to protect the rights of patients and create a social support network for them..$^{5-8}$

Schizophrenia patients should be supported after being discharged from the hospital and during exacerbation of their illness with appropriate medicaments and other treatments to enable them to return to social life and maintain and increase their functionalities. While known and new generation antipsychotic drugs rehabilitate the positive symptoms to a significant extent, they cannot rehabilitate the negative symptoms to the intended extent, and their effects on premorbid functionality remain restricted as well. ${ }^{9-11}$ Therefore, psychiatric rehabilitation, another treatment method, is put into action to enable patients to increase and maintain their functional skills. In recent times, such treatment methods comprising psychiatric rehabilitation, vocational rehabilitation and supported employment, social skills training, cognitive rehabilitation, case management, and psycho-educational training program for patients and their families have become key elements of treatment rather than being assumed to be supplementary functions as was the case before. $^{3-5}$ Such practices help patients tend to their basic daily needs and establish and actively participate in their vital social environment. Moreover, they can also enable patients to have a more independent life, give patients insight into the treatment enhancing their skills so as to cope with the stress they're experiencing, and aid in the adaptation of the patients and their families to the illness. ${ }^{3,9,12,13}$

A diagnosis of schizophrenia indicates many other simultaneous stress resources, because patients with schizophrenia become insensitive to subjective matters rather than objective ones. In the process of the illness, factors such as stigma, depression, and inability to fulfill psychological, physical, and social functions are expected; other psychosocial factors affect the patients as stressors and can cause psychological disturbances. Thus, the individual should develop certain coping skills, including cognitive, emotional, and behavioral pushes in the face of events. While such coping skills could be useful with issues connected with the disorder in social relations and the working place, good coping skills can also positively affect the harmony of an individual and her/his functionality. ${ }^{2,14}$

The treatment of schizophrenia patients requires teamwork. Practices applied by the psychiatric team could help patients maintain their good health status during their stay in clinics and after disharge, adapt to the illnesstreatment end of their social life, and increase or maintain their functional abilities.

\section{Objective}

The research was used to evaluate the effects of employment and membership of people with schizophrenia in an association on their functional skills, treatment compliance, and strategies for coping with stressful situations.

\section{Methods}

This study was planned as a descriptive and cross-sectional study and was conducted in 2010-2011.

\subsection{Locality}

This study was carried out in the Solidarity Association of Schizophrenia Patients and Their Families, Blue Horse Café (a rehabilitation center serving as the commercial enterprise of the Federation of Schizophrenia Associations), Health Research and Application Hospital of Gazi University, and the Education and Research Hospital of Ankara University.

\subsection{Population and Sample}

The psychiatry polyclinics of 3 state universities of Ankara province in Turkey and patients who are members of schizophrenia associations and the affiliated rehabilitation centers were chosen as the research population. The sample was selected from the Solidarity Association of Schizophrenia Patients and Their Families in Ankara and the affiliated Blue Horse Café, the only existing rehabilitation center. One training and research hospital refused to participate in the research and was excluded from the study. The sample was classified into four groups. Group 1 were members of an association and employed; group 2 were members of an association and unemployed; group 3 were non-members and employed; and group 4 were non-members and unemployed. The Solidarity Association of Schizophrenia Patients and Their Families in Ankara supports patients between 18-65 years of age who have a diagnosis of and are monitored for schizophrenia based on DSM criteria. Fifteen people from among the members of this association had confirmed employment; thus, a total of 30 people (15 in each group) were chosen for sample groups 1 and 2. A control group comprised 30 people divided equally between groups 3 and 4 . Total sample size of the research was 60 people, 15 patients in each group.

\subsection{Data Collection}

Data for the study was collected by means of the Personal Information Form, which is comprised of two parts concerning socio-demographic information and treatment compliance; the Medication Adherence Rating Scale (MARS); the Functional Remission of General Schizophrenia Scale (FROGS) (ŞİÖ); and the Styles of Coping with Stress Scale. Participants were classified into four groups as indicated above, and the data collection tools were applied by the researchers in person. The application 
of the data collection tools took 45-60 minutes.

\subsection{Data Assessment}

Data was assessed using SPSS 15.0. The socio-demographic attributes of the participants were grouped and the frequencies and percentages of these attributes were calculated. Scoring, percentage, average and standard deviation values were used in defining the data. The analysis of variance (ANOVA) test was used to compare the continuous variables, and the Tukey test was used as post hoc. The $t$ test was used to compare the two groups. A level of $P \leq 0.05$ was considered statistically significant.

\section{Results}

Participants in groups 1 and 3 included individuals working as civil servants, storekeepers, students, and employees of Mavi At Café $(\mathrm{n}=30)$. Housewives, those who were retired or not working due to disability, and those unemployed were included in groups 2 and $4(n=30)$.

More than half of the participants in group 1 were male (66.7\%), almost all (93.3\%) were unmarried, and 73.3\% were included in the system of Retirement Fund and the Social Security Institution (SGK) and had health insurance. While almost all the individuals in this group (93.3\%) lived with their families, $66.7 \%$ of them were categorized in the middle income class (Table 1).

In relation to the initial diagnosis, more than half of the individuals in group $1(66.7 \%)$ had an illness background of 10 or more years, $60 \%$ had been receiving therapy for 10 or more years, and $46.7 \%$ had been hospitalized 1-3 times (Table 2).

In group 1, 53.3\% received alternative therapy before being medically diagnosed, but no individuals in this group were receiving alternative therapy at the time of the study. More than half $(73.3 \%)$ of the individuals in this group received only drug treatment after the initial diagnosis, but $86.6 \%$ were receiving only drug treatment at the time of the study. $53.3 \%$ of the individuals in this group began their therapies with atypical antipsychotic drugs; at the time of the study, all individuals in the group were continuing their treatment with atypical antipsychotics. More than half $(53.3 \%)$ of the individuals in the group experienced no side effects of therapy, and $73.3 \%$ derived benefits from therapy. Only $13.4 \%$ of the individuals in this group stated that they thought the irregularities in the therapy process were based on circumstances in the family circle; $53.3 \%$ were sufficiently informed about the illness (Table 3 ).

The findings of the research indicate a significant difference in the subscale scoring regarding affected Social Function and Vocational Functionality of patients who are employed and have a membership in an association (Table 4).

Table 5 shows the difference between the side effects of the therapy applied and the scorings of FROGS total, FROGS subscale (Socialization, Health and Therapy, Daily Life Skills, Vocational Functionality), and MARS and SCSS subscales (Seeking Social Support, Submitting Approach, Hopeless Approach, Optimistic Approach, Confident Approach). The table shows that, while there is no statistically significant correlation between the side effects of therapy and the SCSS subscale scores (Optimistic Approach $[P=0.78]$, Confident Approach $[P=0.50]$, Hopeless Approach $[P=0.31]$, Submitting Approach

Table 1. Distribution of Socio-Demographic Attributes

\begin{tabular}{|c|c|c|c|c|c|c|c|c|}
\hline \multirow{3}{*}{$\begin{array}{l}\text { Socio-Demographic } \\
\text { Characteristics }\end{array}$} & \multicolumn{4}{|c|}{ Association Members $(n=30)$} & \multicolumn{4}{|c|}{ Non- Association Members $(n=30)$} \\
\hline & \multicolumn{2}{|c|}{ Employed $(n=15)$} & \multicolumn{2}{|c|}{ Unemployed $(n=15)$} & \multicolumn{2}{|c|}{ Employed $(n=15)$} & \multicolumn{2}{|c|}{ Unemployed $(\mathbf{n}=15$} \\
\hline & No. & $\%$ & No. & $\%$ & No. & $\%$ & No. & $\%$ \\
\hline \multicolumn{9}{|l|}{ Gender } \\
\hline Female & 5 & 33.3 & 6 & 40 & 3 & 20 & 9 & 60 \\
\hline Male & 10 & 66.7 & 9 & 60 & 12 & 80 & 6 & 40 \\
\hline \multicolumn{9}{|l|}{ Marital Status } \\
\hline Married & - & - & 1 & 6.7 & 4 & 26.7 & 2 & 13.3 \\
\hline Single & 14 & 93.3 & 13 & 86.6 & 11 & 73.3 & 9 & 60 \\
\hline Divorced & 1 & 6.7 & 1 & 6.7 & - & - & 4 & 26.7 \\
\hline \multicolumn{9}{|l|}{ Social Security } \\
\hline Social insurance & 3 & 20 & 6 & 40.0 & 4 & 26.7 & 5 & 33.3 \\
\hline Pension fund & 8 & 53.3 & 7 & 46.7 & 11 & 73.3 & 8 & 53.3 \\
\hline Private health insurance & 3 & 20 & 1 & 6.7 & - & - & 2 & 13.4 \\
\hline Green card & 1 & 6.7 & 1 & 6.6 & - & - & - & - \\
\hline \multicolumn{9}{|l|}{ Living Situation } \\
\hline Alone & - & - & 1 & 6.7 & - & - & 1 & 6.7 \\
\hline With relatives & 14 & 93.3 & 13 & 86.6 & 14 & 93.3 & 13 & 86.6 \\
\hline With non-relatives & 1 & 6.7 & 1 & 6.7 & 1 & 6.7 & 1 & 6.7 \\
\hline \multicolumn{9}{|c|}{ Perceived Economic Situation } \\
\hline Good & 5 & 33.3 & 4 & 26.7 & 4 & 26.7 & 5 & 33.3 \\
\hline Middle & 10 & 67.7 & 9 & 60 & 7 & 46.6 & 10 & 67.7 \\
\hline Bad & - & - & 2 & 13.3 & 4 & 26.7 & - & - \\
\hline
\end{tabular}


Table 2. Attributes of Illness and Duration of Therapy of Schizophrenia Patients

\begin{tabular}{|c|c|c|c|c|c|c|c|c|}
\hline & \multicolumn{4}{|c|}{ Association Members $(n=30)$} & \multicolumn{4}{|c|}{ Non- Association Members $(n=30)$} \\
\hline & \multicolumn{2}{|c|}{ Employed (n = 15) } & \multicolumn{2}{|c|}{ Unemployed $(n=15)$} & \multicolumn{2}{|c|}{ Employed (n = 15) } & \multicolumn{2}{|c|}{ Unemployed $(n=15)$} \\
\hline & No. & $\%$ & No. & $\%$ & No. & $\%$ & No. & $\%$ \\
\hline \multicolumn{9}{|c|}{ Disease Duration (y) } \\
\hline $1-4$ & 2 & 13.3 & 1 & 6.7 & 4 & 26.7 & 1 & 6.7 \\
\hline $5-9$ & 3 & 20.0 & 2 & 13.3 & 3 & 20.0 & 4 & 26.7 \\
\hline 10 or more & 10 & 66.7 & 12 & 80 & 8 & 53.3 & 10 & 66.6 \\
\hline \multicolumn{9}{|c|}{ Treatment Duration (y) } \\
\hline $1-4$ & 3 & 20 & 1 & 6.7 & 5 & 33.3 & 3 & 20 \\
\hline $5-9$ & 3 & 20 & 2 & 13.3 & 3 & 20 & 2 & 13.3 \\
\hline 10 or more & 9 & 60 & 12 & 80 & 7 & 46.7 & 0 & 66.7 \\
\hline \multicolumn{9}{|c|}{ Total Hospitalizations } \\
\hline None & 3 & 20 & 3 & 20 & 2 & 13.3 & 3 & 20 \\
\hline $1-3$ & 7 & 46.7 & 6 & 40 & 9 & 60 & 6 & 40 \\
\hline 4 or more & 5 & 33.3 & 6 & 40 & 4 & 26.7 & 6 & 40 \\
\hline
\end{tabular}

$[P=0.90])$, there is a significant difference between the emergence of side effects and the scores of the Seeking Social Support subscale $(P=0.001)$. It was observed that individuals who do not experience side effects from therapy can more effectively cope with stress using the method of seeking social support. Table 4 also shows that there is no significant difference between the FROGS total, FROGS subscale (Socialization, Health and Therapy, Daily Life Skills, Vocational Functionality), and MARS $(P>0.05)$ scores.

\section{Discussion}

This study evaluated the access to employment and membership in associations of people monitored in ambulatory care with a diagnosis of schizophrenia. How activities, gender, illness, and duration and styles of treatment affect their functionality, their treatment compliance, and their styles of coping with stressful situations was assessed.

Close examination revealed that unemployment rates among people diagnosed with schizophrenia are significantly high. ${ }^{2,15,16}$ Such indications support the fact that schizophrenia is a chronic illness that can disturb vocational functionality. ${ }^{6,17}$ Results further indicated a significant difference in subscale scoring regarding the affected social function and vocational functionality of patients who are employed and are members of an association. Half of the employed individuals in the research group were informed and guided in their working life by the rehabilitation center. Such guidance can positively affect their vocational functionality. Patients who are members of an association can become involved in an increased number of personal activities in a socially-supported environment through their membership; they can strike up friendships and gain skills to develop leisure-time activities. The outcomes of a research conducted by Yildiz et al indicated that there was no significant difference between employment and cognitive functions; however, other studies have contradicted these results, indicating that being engaged in a workplace positively affected and improved the social functionality of people with schizophrenia. The current study also reached similar conclusions. ${ }^{2,3,18,19}$ A literature review showed that schizophrenia patients engaged in supported employment less frequently refer to emergency wards and clinics, because they had better treatment compliance, which is accompanied by a more extended duration of remission. Unemployment, on the other hand, brings about nontreatment compliance or possibly fuels the concerns of patients in respect to the stigma resulting from drug use in the workplace. This, in turn, can give rise to a tendency to skip doses, i.e. non-treatment compliance. ${ }^{20-22}$ The current study has shown that having or not having a job has no effects on treatment compliance.

Previous studies have shown that programs such as clubhouses for mental and social rehabilitation or intended for social life and case management implemented for rehabilitation within the society over several years have a positive effect on a patient's clinical improvement; such programs increase patients' social functionalities and enables them to maintain their personal well-being. The current study obtained similar outcomes. ${ }^{23-25}$

Research results indicated that women perform better than men in daily life skills and treatment compliance. Based on these outcomes, it can be said that female patients are in a better position than male patients to meet the needs of daily life; furthermore, they attach more importance to therapy. Many literature sources make reference to studies with similar findings. The research carried out by Emiroğlu confirmed that female patients outperform male patients in daily life routine. ${ }^{3}$ Salokangas et $\mathrm{al}^{26}$ and Cardoso et $\mathrm{al}^{27}$ provided evidence in their related studies that women perform better than men in social adaptation and interpersonal relations. Usall et $\mathrm{al}^{28}$ and Thorup et $\mathrm{al}^{29}$ emphasized in their studies that female patients with schizophrenia generally stand out with better social functionalities. Erol et al, conversely, found no difference in functionality between female and male patients. Such an outcome might have arisen from the fact that there was no difference in the studied factors affecting social functionality. ${ }^{30}$ Women were found to be less adherent to 
Table 3. Types of Therapy Received by Schizophrenia Patients

\begin{tabular}{|c|c|c|c|c|c|c|c|c|}
\hline & \multicolumn{4}{|c|}{ Association Members $(n=30)$} & \multicolumn{4}{|c|}{ Non- Association Members $(n=30)$} \\
\hline & \multicolumn{2}{|c|}{ Employed $(n=15)$} & \multicolumn{2}{|c|}{ Unemployed $(n=15)$} & \multicolumn{2}{|c|}{ Employed $(n=15)$} & \multicolumn{2}{|c|}{ Unemployed $(n=15)$} \\
\hline & No. & $\%$ & No. & $\%$ & No. & $\%$ & No. & $\%$ \\
\hline \multicolumn{9}{|c|}{ Medical diagnosis before alternative treatment application status } \\
\hline Yes & 8 & 53.3 & 746.7 & & 6 & 40 & 5 & 33.3 \\
\hline No & 7 & 46.7 & 853.3 & & 9 & 60 & 10 & 66.7 \\
\hline \multicolumn{9}{|l|}{ Using alternative therapies (at time of study) } \\
\hline Yes & - & - & 1 & 6.7 & 1 & 6.7 & 1 & 6.7 \\
\hline No & 15 & 100 & 1493.3 & & 14 & 93.3 & 14 & 93.3 \\
\hline \multicolumn{9}{|l|}{ First used in treatment type } \\
\hline Drug & 11 & 73.3 & 853.3 & & 11 & 73.3 & 11 & 73.4 \\
\hline Drug-electroconvulsive therapy & 2 & 13.3 & 3 & 20 & 3 & 20 & 2 & 13.3 \\
\hline Drug-electroconvulsive therapy-therapy & 1 & 6.7 & 3 & 20 & 1 & 6.7 & 2 & 13.3 \\
\hline Drug-therapy & 1 & 6.7 & 1 & 6.7 & - & & - & \\
\hline \multicolumn{9}{|l|}{ Therapy type (at time of study) } \\
\hline Drug & 13 & 86.6 & 14 & 93.3 & 13 & 86.6 & 15 & 100 \\
\hline Drug-therapy & 2 & 13.4 & 1 & 6.7 & 2 & 13.4 & - & \\
\hline \multicolumn{9}{|l|}{ Initial medication type } \\
\hline Atypical antipsychotics & 8 & 53.3 & 3 & 20 & 7 & 46.7 & 1 & 6.7 \\
\hline Typical antipsychotics & 6 & 40 & 8 & 53.3 & 5 & 33.3 & 6 & 40 \\
\hline \multicolumn{9}{|l|}{ Medication type at time of study } \\
\hline Atypical antipsychotics & 15 & 100 & 15 & 100 & 14 & 93.3 & 14 & 93.3 \\
\hline Typical antipsychotics & - & - & - & & 1 & 6.7 & 1 & 6.7 \\
\hline \multicolumn{9}{|l|}{ Side effects of treatment } \\
\hline Experienced & 7 & 46.7 & 8 & 53.3 & 6 & 40 & 8 & 53.3 \\
\hline Did not experie nce & 8 & 53.3 & 7 & 46.7 & 9 & 60 & 7 & 46.7 \\
\hline \multicolumn{9}{|l|}{ Utilization level of treatment } \\
\hline Sufficient & 11 & 73.3 & 11 & 73.3 & 9 & 60 & 6 & 40 \\
\hline Partially benefitted & 4 & 26,7 & 3 & 20 & 5 & 33,3 & 8 & 53.3 \\
\hline No benefits & - & - & 1 & 6.7 & 1 & 6.7 & 1 & 6.7 \\
\hline \multicolumn{9}{|l|}{ Negative attitude of the family } \\
\hline Yes & 2 & 13.4 & 1 & 6.7 & 1 & 6.7 & 3 & 20 \\
\hline No & 13 & 86.6 & 14 & 93.3 & 14 & 93.3 & 12 & 80 \\
\hline \multicolumn{9}{|l|}{ Knowledge about disease } \\
\hline Sufficient & 8 & 53.3 & 7 & 46.7 & 3 & 20 & 6 & 40 \\
\hline Partially beneficial & 7 & 46.7 & 7 & 46.7 & 10 & 66.7 & 4 & 26.7 \\
\hline No benefits & - & - & 1 & 6.6 & 2 & 13.3 & 5 & 33.3 \\
\hline
\end{tabular}

therapy than men in the studies carried out by Koc ${ }^{31}$ and Rittmansberger et al, ${ }^{32}$ contrary to the outcome of the current study; the difference between them was confirmed as statistically insignificant. ${ }^{31,32}$ No significant relationship was found between the gender of people with schizophrenia and their behavior in respect to drug usage in the studies conducted by Alıcıkuşu ${ }^{11}$ and Lacro et al. ${ }^{33}$

While there were more female patients in group 4 (no membership and unemployed) compared with the female patient rates in other groups, it is striking that the rates of male patients were higher in other groups representing the contrary case. It can be concluded that such a picture originates from cultural differences. It is a known fact that men are more encouraged and supported than women to work or participate in non-governmental organizations such as associations. It can be argued that this social factor negatively affects female patients with respect to obtaining employment or membership in an association.

While the treatment of a little more than half of the individuals taking part in the research was initiated primarily with typical antipsychotic drugs, almost all individuals ended up using atypical antipsychotics. These outcomes agree with the findings attained in the studies carried out by Belli et al and Simon et al. ${ }^{34,35}$ There can be diverse reasons for such a usage pattern, such as the habitual practices of clinicians and the side effects of typical 
Table 4. Evaluation of FROGS Total and Subscale, MARS and SCSS (Styles of Coping With Stress) Subscale Scorings Wth Association Members who are Employed

\begin{tabular}{|c|c|c|c|c|c|c|}
\hline & $\begin{array}{c}\text { Association } \\
\text { Members and } \\
\text { Employed }(n=15)\end{array}$ & $\begin{array}{l}\text { Association Members } \\
\text { and Unemployed } \\
(n=15)\end{array}$ & $\begin{array}{l}\text { Non-association } \\
\text { Members and } \\
\text { Employed }(n=15)\end{array}$ & $\begin{array}{c}\text { Non-association } \\
\text { Members and } \\
\text { Unemployed }(n=15)\end{array}$ & $\boldsymbol{F}$ & $\boldsymbol{P}$ \\
\hline & Mean \pm SD & Mean \pm SD & Mean \pm SD & Mean \pm SD & & \\
\hline şilö total & $58.3 \pm 7.04$ & $54.1 \pm 9.45$ & $50.8 \pm 12.5$ & $44.2 \pm 18.2$ & 3.36 & $.02 *$ \\
\hline Social functioning & $20.2 \pm 2.24$ & $18.0 \pm 4.24$ & $15.8 \pm 4.65$ & $14.0 \pm 5.95$ & 5.26 & $.001 *$ \\
\hline Health and therapy & $12.5 \pm 2.85$ & $13.8 \pm 2.85$ & $11.6 \pm 3.55$ & $10.5 \pm 4.98$ & 2.21 & .09 \\
\hline Daily living skills & $19.0 \pm 3.76$ & $18.2 \pm 3.49$ & $18.0 \pm 4.73$ & $15.6 \pm 6.72$ & 1.36 & .26 \\
\hline Occupational functioning & $6.53 \pm 1.18$ & $4.00 \pm 1.46$ & $5.26 \pm 1.75$ & $4.00 \pm 2.13$ & 7.88 & $.001^{*}$ \\
\hline MARS & $15.8 \pm 1.72$ & $16.0 \pm 1.33$ & $15.6 \pm 1.71$ & $15.7 \pm 1.86$ & 0.16 & .92 \\
\hline Search social support & $2.81 \pm 0.54$ & $2.96 \pm 0.48$ & $3.03 \pm 0.58$ & $2.67 \pm 0.55$ & 1.35 & .26 \\
\hline Submissive approach & $2.33 \pm 0.54$ & $2.31 \pm 0.65$ & $2.36 \pm 0.22$ & $2.33 \pm 0.64$ & 0.02 & .99 \\
\hline Desperate approach & $2.80 \pm 0.56$ & $2.62 \pm 0.73$ & $2.71 \pm 0.26$ & $2.67 \pm 0.67$ & 0.26 & .85 \\
\hline Optimistic approach & $2.77 \pm 0.64$ & $3.04 \pm 0.54$ & $2.92 \pm 0.36$ & $3.09 \pm 0.40$ & 1.20 & .31 \\
\hline Self-safe approach & $2.94 \pm 0.49$ & $3.00 \pm 0.49$ & $2.93 \pm 0.40$ & $2.91 \pm 0.58$ & 0.10 & .95 \\
\hline
\end{tabular}

Table 5. Evaluation of FROGS Total and Subscale, MARS, and SCSS (Styles of Coping With Stress) Subscale Scores With Reference to Side Effects of Applied Therapy

\begin{tabular}{|c|c|c|c|c|}
\hline & \multirow{2}{*}{$\begin{array}{l}\text { Side Effects }(n=29) \\
\text { Mean } \pm \text { SD }\end{array}$} & \multirow{2}{*}{$\begin{array}{l}\text { No Side Effects }(n=31) \\
\text { Mean } \pm \text { SD }\end{array}$} & \multirow{2}{*}{$t$} & \multirow{2}{*}{$\boldsymbol{P}$} \\
\hline & & & & \\
\hline şiLÖ total & $50.5 \pm 14.9$ & $53.0 \pm 11.5$ & -0.72 & 0.47 \\
\hline Social function & $16.6 \pm 5.67$ & $17.4 \pm 4.20$ & -0.62 & 0.53 \\
\hline Health and therapy & $12.2 \pm 4.07$ & $12.0 \pm 3.53$ & 0.24 & 0.80 \\
\hline Daily living skills & $16.9 \pm 5.70$ & $18.4 \pm 3.84$ & -1.20 & 0.23 \\
\hline Occupational functioning & $4.72 \pm 1.96$ & $5.16 \pm 1.93$ & -0.86 & 0.38 \\
\hline MARS & $15.4 \pm 1.70$ & $16.1 \pm 1.59$ & -1.52 & 0.13 \\
\hline Search social support & $2.62 \pm 0.53$ & $3.09 \pm 0.46$ & -3.61 & $0.001^{*}$ \\
\hline Submissive approach & $2.32 \pm 0.56$ & $2.34 \pm 0.50$ & -0.11 & 0.90 \\
\hline Desperate approach & $2.78 \pm 0.65$ & $2.63 \pm 0.49$ & 1.01 & 0.31 \\
\hline Optimistic approach & $2.93 \pm 0.39$ & $2.97 \pm 0.59$ & -0.27 & 0.78 \\
\hline Self-safe approach & $2.97 \pm 0.49$ & $2.92 \pm 0.49$ & -0.66 & 0.50 \\
\hline
\end{tabular}

antipsychotic drugs. The current study revealed that type of atypical or typical antipsychotic drug had no effect on functionality or treatment compliance. Similarly, Kayahan et al found no significant difference between groups using typical and atypical drugs in terms of improvement in functionality. ${ }^{36}$ A difference was found between type of therapy and therapy adherence in a study carried out by Ascher-Svanum et al. ${ }^{37}$ Conversely, Koç ${ }^{31}$ and Diaz et $\mathrm{al}^{38}$ showed that the type of antipsychotic drugs used had no effect on treatment compliance. Contrary to the findings in the current research, the study of Soykan showed that the usage of atypical antipsychotic drugs affected functionality and the treatment compliance in a positive way. ${ }^{39}$

It was seen in the literature sources that patients with psychiatric disorders often seek alternative remedies, (amulets, healers, visits to tombs of saints, melting lead to break evil spells, usage of traditional drugs, etc.) before participating in medical therapy. ${ }^{40-42}$ The outcomes of the current study support such findings.

Based on the findings, it can be concluded that there is no significant difference between duration of illness, functionality fields, and treatment compliance. Similar outcomes were obtained in other studies as well. In the research conducted by Tatlidil, no significant correlation was found between duration of illness and functionality. ${ }^{43}$ Glass, on the other hand, argues that psychotic patients showing a tendency toward becoming chronic have low functionality levels. ${ }^{44}$ Aker et al are also of the opinion that a longstanding illness could affect treatment compliance in a negative way. ${ }^{45}$ Patients with a longstanding illness usually think that they will never be rehabilitated and that the implemented therapy will not be effective; such views can negatively affect the treatment process. The social support of other people could diminish as the duration of the illness lengthens; such a circumstance could cause delays or halts in regular controls that are of great importance to treatment compliance and consequently affect both the course and degree of the illness in a negative manner. ${ }^{46}$ Lacro et al, however, argue that a short illness duration can cause non-treatment compliance. ${ }^{34}$

The research showed that patients receiving treatment for 5-9 years scored better in social functionality and therapy adherence than other groups. The results obtained by Belli et al and Saylan et al also indicated that shortterm treatment negatively affects the regular course of treatment. ${ }^{34,47}$

Results of the current study indicated that there is no significant difference between treatment side 
effects and functionality. Some studies in the literature support these findings, but others indicate contradictory outcomes. While Tatlidil could identify no correlation between extrapyramidal side effects, weight gain, and social functionality, Hofer et al showed that weight gain, extrapyramidal symptoms, sedation, and hyper-salivation negatively affected quality of life and social functionality, and the extrapyramidal side effects negatively affected vocational functionality. ${ }^{43,46}$ Güneş showed that social functionality scores decreased when drug side effect level increased. ${ }^{2}$ The current research found that the side effects of therapy had no effect on adherence; however, the outcomes of the study carried out by Aker et al indicated that therapy side effects did affect treatment compliance. ${ }^{45}$ As there are no other studies in this area, there is no decisive conclusion about the effects of therapy on treatment compliance.

An examination of the scores associated with the subscale of Styles of Coping with Stress (Seeking Social Support, Submitted Approach, Hopeless Approach, Optimistic Approach, Confident Approach) confirmed that participants who were initially treated with atypical antipsychotic drugs just after diagnosis and had an illness background of 5-9 years used optimistic and confident approaches more effectively than other individuals. It was also observed that patients supposing that the applied therapy had no side effects sought social support in a more effective way. The research carried out by Özcan et al indicated that every patient exhibits at least one behavior intended for coping with stress. ${ }^{40}$ This outcome is consistent with the findings indicated in literature sources. ${ }^{48-50}$ This is an indication that, contrary to general belief, schizophrenia patients are not individuals capitulated to their illness, accepting the situation, and living in a sense of paralysis. ${ }^{41}$ Ultimately, being involved in an association or at a workplace as well as many other factors can affect a patient's functionality, treatment compliance, and styles of coping with stress.

\section{Conclusion}

The research sample was split into four groups: members of an association and employed; members of an association and unemployed; non-members and employed; and non-members and unemployed. While there were more women in the group with no association membership and unemployed, men dominated the group comprised of those having no membership in an association and employed. The usage rate of atypical antipsychotic medicaments was higher than that of typical antipsychotics in the existing therapy. Results of this research indicated that patients who are members of an association and employed have better social and vocational functionality than others.

\section{Authors' Contributions}

Determining the study design, planning, data collection, analyses, and article writing were done by MN and GN. Analyses and article writing were done by BK.

\section{Conflict of Interest Disclosures}

None declared.

\section{Ethical Approval}

Gulhane Military Medical Academy (February 21, 2011; Board of Ethics and Decision No. 1491-1243-11/1539) ethically approved and provided the necessary permission for the study.

\section{Acknowledgments}

The authors acknowledge and appreciate the support of the consultant and the cooperation of the institutions and patients who participated in the study.

\section{References}

1. Yıldız M. Schizophrenia Treatment of Mental and Social Initiatives. In: Ceylan ME, Cetin M, eds. Schizophrenia. Istanbul: İncekara Kağıt Typography; 2009:1403-1413.

2. Güneş D. Objective and Subjective Evaluation of the Quality of Life and Social Functioning of Şizofr new patients. [Thesis]. Istanbul: Bakırköy Prof. Dr. Mazhar Osman Mental Health and Neurological Diseases Training and Research Hospital; 2010.

3. Emiroğlu B. Validity and reliability study of the Turkish version of the Functional Remission in Schizophrenia Patients [Master's thesis]. Istanbul: Maltepe University; 2009.

4. Olfson M, Mechanic D, Hansell S, Boyer CA, Walkup J, Weiden PJ. Predicting medication noncompliance after hospital discharge among patients with schizophrenia. Psychiatr Serv. 2000;51(2):216-222. doi:10.1176/appi.ps.51.2.216.

5. Eryıldız D. The day hospital and rehabilitation center on the ongoing rehabilitation of chronic schizophrenic patients with chronic schizophrenia patients who participate in the program compared in terms of functionality and quality of life [Dissertation]. Istanbul: Bakırköy Prof. Dr. Mazhar Osman Mental Health and Neurological Diseases Training and Research Hospital; 2009.

6. Işık E. Current Schizophrenia. Ankara: Format Typography; 2006.

7. Yıldız M. Psychiatric rehabilitation. In: Community Mental Health of Individuals. 1st ed. Istanbul: Erler Typographyk; 2005:151-164

8. Gülseren L. [Schizophrenia and the family: difficulties, burdens, emotions, needs]. Turk Psikiyatri Derg. 2002;13(2):143-151. [Turkish].

9. Sadock BJ, Sadock VA. Comprehensive textbook of psychiatry. Aydın H, Bozkurt A, Trans. Ankara: Sun Bookstore; 2007.

10. Öztürk MO, Uluşahin A, eds. Mental Health Disorders. 11th ed. Ankara: Tuna Typography; 2008 :306-317.

11. Alıcıkusu HA. Attitudes with the psychiatric treatment of schizophrenia [Master's thesis]. Gaziantep: Gaziantep University; 2009.

12. Yazıcı A, Coşkun S. (Bakırköy Mental Health and Diseases Hospital) day hospital and rehabilitation centre patient profile and study program. Anatolian Journal of Psychiatry. 2008;9(1):21-23.

13. Andreasen NC, Carpenter WT Jr., Kane JM, Lasser RA, Marder SR, Weinberger DR. Remission in schizophrenia: proposed criteria and rationale for consensus. Am J Psychiatry. 2005;162(3):441-449. doi:10.1176/appi.ajp.162.3.441.

14. Myin-Germeys I, Krabbendam L, Jolles J, Delespaul PA, van Os J. Are cognitive impairments associated with sensitivity to stress in schizophrenia? An experience sampling study. Am J Psychiatry. 2002;159(3):443-449. doi:10.1176/appi. ajp.159.3.443

15. Akpınar Ş. Applies to Schizophrenia Quality of Life Problem Solving Skills Development Program and Effects of Social Functioning Levels [Master's Thesis]. Sivas: Cumhuriyet University; 2008.

16. Barlas ÜG, Işı Ö. Evaluation of the Effectiveness of Patient with Chronic Schizophrenia Psychosocial Skills Training. Maltepe University School of Nursing Science and Arts Magazine, 
Special Issue Symposium; 2010:312-317.

17. Dilbaz N, Darçın EA. Treatment of schizophrenia and substance use disorder comorbid patients. Clin Psychopharmacol Bull. 2011;21:80-90.

18. Angell B, Test MA. The relationship of clinical factors and environmental opportunities to social functioning in young adults with schizophrenia. Schizophr Bull. 2002;28(2):259271

19. Yıldız M, Kutlu H, Tural Ü. Demographic and clinical characteristics of cognitive function is affected in schizophrenia? Clin Psychopharmacol Bull. 2011;21(2):131-139.

20. Cobanoglu D, Aker T, Çobanoğlu N. Schizophrenia and other psychotic disorders in patients with treatment compliance issues. Dusni Adam. 2003;16(4):211-218.

21. Henry AD, Lucca AM, Banks S, Simon L, Page S. Inpatient hospitalizations and emergency service visits among participants in an Individual Placement and Support (IPS) model program. Ment Health Serv Res. 2004;6(4):227-237.

22. Compton MT, Rudisch BE, Craw J, Thompson T, Owens DA. Predictors of missed first appointments at community mental health centers after psychiatric hospitalization. Psychiatr Serv. 2006:57(4):531-537. doi:10.1176/ps.2006.57.4.531.

23. Chan $H$, Inoue $S$, Shimodera $S$, et al. Residential program for long-term hospitalized persons with mental illness in Japan: Randomized controlled trial. Psychiatry Clin Neurosci. 2007;61(5):515-521. doi:10.1111/j.1440-1819.2007.01701.x.

24. Sevinçok L. Psychosocial Causes of Schizophrenia Etiology. 2000. Schizophrenia Series 15.

25. Yazıcı A. Mental Training in family and group therapy in patients with schizophrenia. Spring Symposium 2008;4:3-20.

26. Salokangas RK, Honkonen T, Stengard E, Koivisto AM. To be or not to be married--that is the question of quality of life in men with schizophrenia. Soc Psychiatry Psychiatr Epidemiol. 2001;36(8):381-390.

27. Cardoso CS, Caiaffa WT, Bandeira M, Siqueira AL, Abreu $\mathrm{MN}$, Fonseca JO. Factors associated with low quality of life in schizophrenia. Cad Saude Publica. 2005;21(5):1338-1340. doi:10.1590/S0102-311X2005000500005.

28. Usall J, Araya S, Ochoa S, Busquets E, Gost A, Marquez M. Gender differences in a sample of schizophrenic outpatients. Compr Psychiatry. 2001;42(4):301-305.

29. Thorup A, Petersen L, Jeppesen P, et al. Gender differences in young adults with first-episode schizophrenia spectrum disorders at baseline in the Danish OPUS study. J Nerv Ment Dis. 2007;195(5):396-405. doi:10.1097/01. nmd.0000253784.59708.dd

30. Erol A, Ünal KE, Tunç AE, Mete L. Predictors of social functioning inschizophrenia.TurkishJ Psychiatry. 2009;20(4):313-321.

31. Koç A. Compliance to treatment in patients with chronic psychosis and Treatment Compliance with the Associated Factors considered not to be [Thesis]. Ankara: Gazi Hospital; 2006.

32. Rittmannsberger $H$, Pachinger $T$, Keppelmuller $P$, Wancata J. Medication adherence among psychotic patients before admission to inpatient treatment. Psychiatr Serv. 2004;55(2):174-179. doi:10.1176/appi.ps.55.2.174.

33. Lacro JP, Dunn LB, Dolder CR, Leckband SG, Jeste DV. Prevalence of and risk factors for medication nonadherence in patients with schizophrenia: a comprehensive review of recent literature. J Clin Psychiatry. 2002;63(10):892-909.

34. Belli H, Özçetin A, Ertem Ü, et al. Some socio-demographic characteristics and factors associated with schizophrenia treatment. Anadolu Psikiyatri Derg. 2007;8:102-112

35. Simon AE, Peter M, Hess L, Valterio C. Antipsychotic use in patients with schizophrenia treated in private psychiatry. Swiss Med Wkly. 2005;135(7-8):109-115.

36. Kayahan B, Veznedaroğlu B, Öztürk O, Ersoy AM. Atypical
Research Highlights

What Is Already Known?

There is only one place in Ankara, which is the capital of our country, for schizophrenic patients to provide therapy and job opportunities. At the same time, this is the first and only protected work place. Schizophrenic patients and their relatives. At the same time, there is a psychiatrist who carries out therapies. The schizophrenic patients were more functional.

\section{What This Study Adds?}

Increasing the number of protected workplaces will greatly contribute to the treatment of schizophrenia patients and their families.

antipsychotic drugs in schizophrenia mini mental state examination (CBE) effect of comparative with typical antipsychotics - natural follow-up study. Anadolu Psikiyatri Derg. 2004;5:206-212.

37. Ascher-Svanum H, Zhu B, Faries DE, Lacro JP, Dolder CR, Peng X. Adherence and persistence to typical and atypical antipsychotics in the naturalistic treatment of patients with schizophrenia. Patient Prefer Adherence. 2008;2:67-77.

38. Diaz E, Neuse E, Sullivan MC, Pearsall HR, Woods SW. Adherence to conventional and atypical antipsychotics after hospital discharge. J Clin Psychiatry. 2004;65(3):354-360.

39. Soykan A. Overview of Atypical Antipsychotic. Clin Psychiatry. 2000;1:13-15

40. Özcan EM, Gürgen F, Türkeş C. Patients with schizophrenia Coping Behaviors. Düșünen Adam. 1999;12(3):35-40.

41. Bahar A. Evaluation of non-medical help seeking behaviour in psychiatric patients. New Symposium. 2010;48(3):216-222.

42. Güleç G, Yenilmez Ç, Ay F. Description search behavior of disease and cure patients presenting to a psychiatric clinic in an Anatolian city. Klinik Psikiyatri. 2011;14:131-142.

43. Tatlıdil E. The Effect of Social Functioning of Symptomatology in Schizophrenic Patients [Thesis]. Ankara: Ankara University; 2008.

44. Glass RM. Mental disorders quality of life: inequality of insurance coverage. JAMA. 1995;274:1557.

45. Aker T, Üstünsoy S, Kuğu N, Yazıcı A. Psychotic disorder rating scale mismatch and drug therapy compliance in patients. 36th National Psychiatry Congress; 2000; Antalya.

46. Hofer A, Kemmler G, Eder U, Edlinger M, Hummer $M$, Fleischhacker WW. Quality of life in schizophrenia: the impact of psychopathology, attitude toward medication, and side effects. J Clin Psychiatry. 2004;65(7):932-939.

47. Saylan M, Alptekin K, Akdemir A, Tetik E, Korb FA. The intercontinental schizophrenia outpatient health outcomes (IC$\mathrm{SOHO})$ study: baseline clinical and functional characeristics and antipsychotic use patterns in Turkey. Bull Clinical Psychopharmacol. 2004; 14:132-42.

48. Gürhan N. Schizophrenic patients, social support, disease, and evaluation of coping with stress [PhD Thesis]. Ankara: Ankara Hacettepe University; 1995.

49. Kemp R, Kirov G, Everitt B, Hayward P, David A. Randomised controlled trial of compliance therapy. 18-month follow-up. $\mathrm{Br}$ J Psychiatry. 1998;172:413-419.

50. Brazo P, Dollfus S, Petit M. [Anti-hallucinatory coping strategies in schizophrenia]. Ann Med Psychol (Paris). 1995;153(7):456459 . 